\title{
ARTIKELEN
}

\section{Een praktische benadering van executoriale verkoop van onroerende zaken}

\author{
Mr. H.Th.M. Burgers ${ }^{*}$
}

\section{Inleiding}

Bij een openbare verkoop van onroerende zaken hier te lande kunnen zich incidenten voordoen, waarop niet gerekend is en die om een praktische en correcte oplossing vragen. Ook zijn er in de procedures gewoonten geslopen, waarbij men zich kan afvragen of deze wel juridisch houdbaar zijn. Hierna zal ik enkele van die incidenten en gewoonten bespreken en aanbevelingen aandragen, waarbij steeds als uitgangspunt wordt genomen dat moet worden geprobeerd om een zo hoog mogelijke opbrengst in het belang van de schuldeiser én debiteur te bereiken.

Vooraf dit: een executoriale verkoop van onroerende zaken geschiedt in twee fasen, eerst bij opbod en vervolgens bij afmijning (art. 519 Wetboek van Rechtsvordering van Curaçao, hierna ' $\mathrm{Rv}$ '). Meer zegt de wet daarover niet, maar de praktijk van tientallen jaren is als volgt.

Fase 1: de executant verlangt een minimumbod, waarop de aanwezigen hoger kunnen bieden. Op een gegeven moment houdt het bieden op en de notaris constateert in zijn proces-verbaal dat het hoogste bod is uitgebracht door persoon X. Vervolgens wordt in fase 2 dit hoogste bod door de executant met een groot bedrag verhoogd en begint vanaf dit verhoogde bedrag het afmijnen: het langzaamaan aftellen van de bedragen. Aan degene die bij een bedrag als eerste 'mijn' roept, kan de executant het pand in koop toewijzen. Pas na de toewijzing is de obligatoire overeenkomst van koop gesloten.

Bij een vrijwillige openbare verkoop kan men kiezen tussen het systeem van opbod en afmijning dan wel het systeem waarbij de hoogste bieder de koper wordt. Hetgeen hierna volgt geldt voor de executoriale verkoop krachtens de hypotheekakte.

\section{De aankondiging van de veiling}

Een executoriale verkoop door de hypotheekhouder op grond van artikel 3:268 BW begint voor het publiek met een advertentie in de dagbladen ten minste dertig dagen vóór de veiling. De wettelijke eis van slechts één aankondiging in een te Curaçao verschijnend nieuwsblad (art. $516 \mathrm{Rv}$ ) is in de praktijk te zwak gebleken en daarom wordt in de praktijk de aankondiging meerdere malen gepubliceerd. Wanneer men een bijzonder object (hotel of

* Mr. H.Th.M. Burgers is oud-notaris. 
fabriek) in het openbaar moet verkopen, dan behoort mijns inziens de executant in samenwerking met de notaris ervoor te zorgen dat de veiling ook wordt aangekondigd in de vakbladen, die gelezen worden door hen die werkzaam zijn in de branche van dat bijzondere object, niet alleen in Curaçao maar ook daarbuiten. Aankondigingen op de websites van de bank en de notaris zijn ook nuttig. De executant kan ook actief zoeken naar mogelijk gegadigden en hen benaderen om de veiling onder hun aandacht te brengen.

Sommige notarissen vermelden het minimumbedrag waarmee de executant de biedingen wil laten beginnen, anderen doen dit niet. Het vermelden van zo'n minimumbedrag is in het kader van informatieverschaffing wenselijk en heeft tot gevolg dat het niet toegestaan is om de biedingen met een lager bedrag te starten, ook niet ingeval niemand bereid is dit beginbedrag te bieden. Zou niemand het beginbedrag willen bieden, dan stopt de openbare verkoop en moet de veilingprocedure opnieuw gestart worden. Niet-vermelding van het minimumbod dat verlangd wordt leidt tot onzekerheid en tot vragen aan het notariskantoor.

Het zou ook kunnen leiden tot een ontoelaatbare handelwijze zoals het telefonisch informeren over het minimumbod en bij onvoldoende belangstelling ter veiling tot het verlagen van het minimumbedrag dat verlangd wordt. Daardoor worden belangstellenden, die het telefonisch doorgegeven minimumbod iets te hoog vonden, maar wél bereid zouden zijn het ter veiling verlaagde minimumbedrag te betalen, belemmerd aan de veiling deel te nemen. De notaris moet weigeren hieraan mee te doen.

Wanneer men ervan uitgaat dat het wenselijk is een minimumbedrag in de veilingaankondiging op te nemen, dan rijst de vraag welk bedrag vermeld zou moeten worden. Enkele banken gaan uit van de hoogte van de schuld zonder rekening te houden met de waarde van het te veilen pand. Dit leidt er bij een hoge schuld vaak toe dat een bod verlangd wordt boven de marktwaarde, waardoor de veiling bij voorbaat mislukt en later opnieuw moet worden georganiseerd. Deze -nodeloze! - kosten van de mislukte veiling komen voor rekening van de bank, die zij ingevolge de leningsvoorwaarden weer in rekening brengt aan de debiteur. Deze benadering is derhalve onwenselijk ingeval de schuld hoog is.

Andere banken gaan uit van de door een taxateur geschatte executiewaarde als minimumbod. De executiewaarde is de verwachte opbrengst bij een gedwongen openbare verkoop, die meestal op zeventig procent van de verkoopwaarde gesteld wordt. De gedachte hierachter is dat een verkoop onder de executiewaarde de banken en de debiteur benadeelt, hetgeen op zich juist is. Toch pleit ik voor het opnemen van een lager bedrag als minimumbod teneinde meer belangstellenden aan te trekken. Ervaring uit de praktijk leert, dat bij een groot aantal belangstellenden de opbrengst veel hoger uitkomt. Ik heb meegemaakt dat bij een veiling van een pand, waarvoor twee personen belangstelling toonden, de uiteindelijke koper afmijnde op een bedrag dat ruim tien procent hoger was dan hij oorspronkelijk had willen bieden, enkel en alleen omdat hij bang was dat de ander er met het pand vandoor zou gaan. Achteraf bleek dat de andere partij alleen maar nieuwsgierig was naar de gang van zaken bij een veiling en niet de intentie had een bod te doen.

Zou er ondanks een laag minimumbedrag weinig belangstelling zijn en het hoogste bod onder het bedrag van de executiewaarde uitkomen, dan moet de executant overwegen of 
hij het pand in koop toewijst dan wel afwijst. Bij afwijzing van het bod zal er een nieuwe veiling gehouden moeten worden, welke extra kosten met zich zal meebrengen. Het is naar mijn mening verdedigbaar dat de executant het pand in koop kan toewijzen, indien het bod gelijk is aan of hoger is dan de executiewaarde verminderd met de kosten van zo'n tweede veiling. In dat geval benadeelt de executant de debiteur niet en wordt de schuld niet hoger door de bijkomende rente over de periode tussen de eerste en tweede veiling.

In veel advertenties kan men lezen dat de executant zich het recht voorbehoudt om de veiling uit te stellen en op een andere datum voort te zetten dan wel te stoppen. Mijns inziens is dit voorbehoud niet in strijd met de bepalingen van het Wetboek van Burgerlijke Rechtsvordering. Artikel $516 \mathrm{Rv}$ vermeldt slechts dat de verkoop niet eerder dan dertig dagen na de aankondiging kan plaatsvinden. Een minimumtermijn zonder maximum.

Vanuit een praktisch oogpunt is er niets op tegen om dit voorbehoud te maken. Het kan zijn dat de debiteur verlenging van de termijn vraagt om alsnog de kans te krijgen zijn schuld in te lossen. Wanneer men weet dat een aanvrage door een aspirant-koper voor een hypotheek vaak langer duurt dan de vijf weken die nodig zijn om een executoriale verkoop te organiseren, dan is een verlenging van de termijn waarbinnen geveild wordt ook op zijn plaats. Naast het voorbehoud is het aan te bevelen om het begin van de termijn tussen de eerste advertentie en de dag van veiling op zes of meer weken te stellen. Zou de executant echter te lang dralen met het voortzetten van de executie, dan kan elke beslaglegger of hypotheekhouder het Gerecht in Eerste Aanleg verzoeken een termijn vast te stellen waarbinnen de veiling moet plaatsvinden (art. $545 \mathrm{Rv}$ ).

\section{Twee kopers roepen tegelijk 'mijn'}

Wat nu ingeval twee personen tegelijkertijd bij de afmijning 'mijn' roepen of niet uitgemaakt kan worden wie de eerste roeper was? Naar mijn mening moeten de veilingvoorwaarden een bepaling bevatten dat in zo'n geval de executant direct opnieuw met de afmijning zal beginnen. In een enigszins vergelijkbaar, in de dagbladen breed uitgemeten, praktijkgeval werd besloten de verkoop te stoppen en een geheel nieuwe veiling te organiseren.

Vergelijkbaar hiermee is het geval waarin de executant direct ter veiling beslist om degene die 'mijn' geroepen heeft niet te aanvaarden als koper, hetzij omdat al direct vaststaat dat hij niet de koopsom en kosten kan voldoen, hetzij omdat hij daarvoor geen garantie kan afgeven, hetzij om andere redenen (bijvoorbeeld de aspirant-koper was voor eenieder waarneembaar onder invloed van alcohol). Ook voor dit soort gevallen dienen de veilingvoorwaarden een bepaling te bevatten dat de executant direct opnieuw tot afmijning kan overgaan.

In de standaardvoorwaarden bij een executoriale veiling komt de bepaling voor dat iedere bieder bij de opbieding en ook degene die 'mijn' roept gehouden is aan zijn bod. Nadat 'mijn' is geroepen verlaten de belangstellenden meestal het kantoor, zonder dat men weet wie dat zijn. Daardoor is het moeilijk om iemand aan zijn bod te houden ingeval de 'mijn'roeper niet wordt aanvaard als koper. Het verdient in verband hiermee aanbeveling dat de executant vóóraf de personalia van de belangstellenden en de bewijzen dat men een 
bepaald bedrag kan betalen, controleert. Bij veilingen waar men een groot aantal belangstellenden verwacht is het zinvol om hen een paar dagen vóór de veiling te laten inschrijven onder overlegging van de bewijzen dat men de koopsom en kosten kan betalen.

In overeenstemming met artikel 527 en 529 Rv bepalen de veilingvoorwaarden dat ingeval de koper op de veiling het pand niet afneemt, er een herveiling ten laste van de koper zal plaatsvinden, waarbij de niet-presterende koper aansprakelijk wordt voor het verschil tussen zijn bod en de lagere opbrengst bij de herveiling. Een hogere opbrengst komt ten goede aan de executant en of debiteur.

\section{Rol van de notaris}

De verkoop gebeurt door de executant, die de belangrijkste beslissingen neemt. De rol van de notaris is het opmaken van het proces-verbaal van hetgeen zich afspeelt ter veiling. Het Wetboek van Burgerlijke Rechtsvordering deelt aan de notaris nog enkele extra taken in het kader van de veiling toe. De notaris stelt in overleg met de executant de veilingvoorwaarden vast en zendt deze aan de beslagleggers en beperkt gerechtigden (art. $517 \mathrm{Rv}$ ). Verder moet hij zo mogelijk uiterlijk een dag na de verkoop hiervan kennisgeven aan de geëxecuteerde en de beslagleggers (art. $523 \mathrm{Rv}$ ) en moet hij de koopsom ontvangen.

Moet de notaris ook controleren of de hypotheekakte, krachtens welke de executant veilt, wel geldig is? Mijns inziens moet hij dat wel, omdat hij ervoor in moet staan dat de koper rechthebbende wordt. Het kan zijn dat de hypotheek is gevestigd voor een vaste lening, die later is afgelost met een nieuwe vaste lening van dezelfde schuldeiser. Omdat de hypotheek een van de vordering afhankelijk recht is, is zij vervallen door de aflossing van de vaste lening en het aangaan van de nieuwe lening. Het zekerheidsrecht bestaat dan niet meer. Toch veilen zou misbruik van een ogenschijnlijk bestaand hypotheekrecht, dat in werkelijkheid niet bestaat, betekenen. De executant behoort aan de notaris alle informatie te geven welke deze in dit kader verlangt.

In de praktijk is het voorgekomen dat een hypothecaire schuldeiser zijn vordering in de boekhouding' had overgedragen aan een andere financiële instelling zonder dat daaraan een schriftelijke overeenkomst van cessie ten grondslag lag. De financiële instelling wilde tot openbare verkoop overgaan, doch het Gerecht in Eerste Aanleg besliste dat zij zonder de cessie daartoe niet bevoegd was. Wanneer een schuldeiser meedeelt krachtens een cessie de hypothecaire schuldeiser te zijn geworden, dan behoort de notaris dit te onderzoeken.

Bij krediethypotheken is het extra opletten geblazen, omdat een krediet niet overgedragen kan worden. Eerst zal het krediet opgezegd moeten worden en de vordering uit het krediet moeten worden vastgesteld en vervolgens kan deze als een vaste vordering worden gecedeerd.

Banken hebben vaak een dochtermaatschappij, die bevoegd is tot het handelen in onroerend goed. Moet de notaris meewerken aan een veiling, waarbij de executant het pand toewijst aan haar eigen onroerendgoedmaatschappij? Hier moet de notaris extra waakzaam zijn, omdat de verleiding bestaat om ten koste van de debiteur het pand tegen een te laag 
bedrag te verkopen aan de dochtermaatschappij. In ieder geval dient de notaris een taxatierapport te verlangen met daarop aangegeven de executiewaarde. Het mag niet zo zijn dat het te veilen pand ruim onder de executiewaarde wordt toegewezen aan de onroerendgoedmaatschappij van de bank. Kan de notaris weigeren het proces-verbaal te ondertekenen? Nee, in zo'n geval moet de notaris het proces-verbaal van de veiling afmaken en ondertekenen; hij moet namelijk constateren wat er ter veiling gebeurd is. Hij kan echter wél weigeren het proces-verbaal na de betaling van de koopsom in te schrijven in de openbare registers. De executant en de koper dienen dan in kort geding de inschrijving te eisen en de rechter zal dan beslissen.

Moet de notaris de garantie, die door de aspirant-koper wordt overgelegd controleren? In wezen behoort deze controle door de executant te worden gedaan, zeker ingeval de executant een bankinstelling is. De notaris kan daarbij behulpzaam zijn en hij zal de bewijzen daarvan in zijn dossier bewaren. Is de executant een particulier, dan zal de notaris de garantie op haar merites moeten beoordelen en de executant van onpartijdig advies dienen. De beslissing tot aanvaarding van de garantie ligt dus bij de executant.

Mag een notaris een stichting particulier fonds, waarvan hij de begunstigde is, als koper laten optreden bij de veiling? Het risico bestaat dat de notaris zijn kennis misbruikt en het te veilen pand te goedkoop inkoopt ten koste van de debiteur en executant. De notaris behoort het belang der partijen te dienen en geen eigen belang te hebben bij zijn handelen. Om deze reden verbiedt artikel 3:43 lid 1 sub b BW een dergelijk handelen en verklaart deze nietig. De bedoeling van dit artikel is bescherming van de personen tegen wie de handeling (i.e. openbare verkoop) is gericht, ook indien zij is verricht door tussenkomende personen. De stichting particulier fonds is zo'n tussenkomende persoon. Blijkens het commentaar bij artikel 3:43 BW (in Tekst \& Commentaar Burgerlijk Wetboek) ziet 'door tussenkomende personen' ook op 'gevallen van middellijke vertegenwoordiging (de tussenpersoon handelt op eigen naam maar voor rekening van de ander)'.

\section{Compensatie van de koopsom}

De koopsom moet aan de notaris worden voldaan (art. 3:270 lid 1 BW en art. $524 \mathrm{Rv}$ ). Hierdoor is het niet mogelijk voor de executant die zelf het onroerend goed koopt, om zijn verplichting tot betaling van de koopsom te verrekenen met zijn overige niet door hypotheek gedekte vorderingen. Hetzelfde geldt voor een andere schuldeiser van de debiteur.

Wat als de koopsom niet aan de notaris wordt voldaan en de executant besluit om in strijd met artikel 3:270 lid $1 \mathrm{BW}$ en artikel $524 \mathrm{Rv}$ te compenseren? Is de veiling dan nietig en wordt de koper 'dus' geen eigenaar? De notaris mag dan niet de verklaring aan de bewaarder der openbare registers afgeven dat de koopsom in zijn handen is, en zonder die verklaring weigert de bewaarder de inschrijving van het proces-verbaal van toewijzing (art. 525 lid $2 \mathrm{Rv}$ ) en wordt de koper dus geen eigenaar. De Hoge $\mathrm{Raad}^{1}$ heeft zich over deze vraag gebogen in een geval waarin de notaris ten onrechte had verklaard dat de koopsom onder hem berustte, terwijl de koper de schuld van de debiteur rechtstreeks aan de executant had 
voldaan en het pand werd geleverd aan de koper door de inschrijving van het proces-verbaal van toewijzing. Uit dit arrest blijkt dat de ingeschreven schuldeisers uit de koopsom zijn voldaan. Derhalve een zuivering, doch niet volgens de regels, terwijl geen van de schuldeisers schade had geleden. De Hoge Raad oordeelde dat de omstandigheden dat de notaris de koopsom niet had ontvangen en dat de nettokoopsom ook niet bij een bewaarder was gestort (zoals art. $551 \mathrm{Rv}$ en art. 3:270 lid 3 BW eisen) de veiling niet ongeldig maakten. Zou de zuivering niet hebben plaatsgevonden, dan zou de notaris wegens verzuim van zijn ambtsplicht kunnen worden aangesproken voor de schade die schuldeisers van de geëxecuteerde daardoor zouden hebben geleden.

\section{Veel veilingen op één vaste veilingdag}

De wens heeft bestaan om verscheidene veilingen door meer notarissen op een vaste veilingdag te laten plaatsvinden, zoals dat in Nederland (onder meer Amsterdam en Rotterdam) gebruikelijk is.

Het is algemeen bekend dat in Nederland onroerendgoedhandelaren dergelijke veilingen middels afspraken misbruiken. ${ }^{2}$ Een Nederlandse onroerendgoedhandelaar heeft mij uitgelegd dat de handelaren met elkaar overeenkomen op welk huis zij niet bieden, waardoor de prijs niet wordt verhoogd en één van hen het huis voor een (te) laag bedrag kan kopen. Wanneer er twintig huizen op een ochtend of middag snel achter elkaar geveild gaan worden, dan is het gemakkelijk een dergelijke, verboden afspraak te maken en iedere handelaar met één of meer te goedkoop gekochte huizen naar huis te laten gaan, hetgeen ten koste van de debiteur en executant gaat.

Het moge duidelijk zijn dat deze toestanden ongewenst zijn, ook al zijn zij niet geheel uit te bannen, ook niet wanneer er slechts één pand op een ochtend wordt geveild.

\section{Conclusies}

Samengevat kan men het volgende concluderen:

1 De wettelijke eis van slechts één aankondiging van de executie in een dagblad is veel te zwak en de zorgplicht van de executant en notarissen gebiedt dat zij meer moeten adverteren en bij speciale objecten zelfs in de daartoe geëigende bladen.

2 De wettelijke termijn van dertig dagen tussen de eerste aankondiging van de verkoop en de verkoop zelve is te kort, mede omdat het aanvragen van een hypothecaire financiering en de verkrijging daarvan tegenwoordig vaak meer dan vijf weken duurt. Een termijn van zes weken of meer is aan te bevelen.

3 Het voorbehoud van de executant om een veiling te mogen uitstellen en later te vervolgen is niet verboden en om praktische redenen gewenst.

4 Het is aan te bevelen om een laag minimumbod in de aankondiging op te nemen om veel geïnteresseerden te trekken. Toewijzing aan de bieder kan in sommige gevallen

2 I. Visser, De executoriale verkoop van onroerende zaken door de hypotheekhouder (diss. Groningen), p. 39 e.v. en de aldaar vermelde literatuur. Het proefschrift is te raadplegen op www.rug.nl. 
onder de executiewaarde geschieden ter voorkoming van een tweede veiling, mits dit niet schadelijk is voor de geëxecuteerde en/of ingeschreven schuldeisers. Ingeval een tweede veiling, waarbij het bod werd verlaagd, ook niet tot resultaat leidt, zal geprobeerd moeten worden om met een drastische verlaging van het minimumbod belangstellenden te trekken.

5 In de veilingvoorwaarden dient opgenomen te worden dat ingeval twee personen tegelijk 'mijn' roepen of niet uitgemaakt kan worden wie het eerste 'mijn' roept, de executant de afmijning direct opnieuw zal beginnen.

6 In de veilingvoorwaarden dient opgenomen te worden dat ingeval de executant de hoogste bieder ('mijn'-roeper) om wat voor geldige reden ook niet aanvaardt, de executant direct bevoegd is de afmijning opnieuw te doen plaatsvinden.

7 De executant moet vóór de verkoop de garanties van de mogelijke bieder controleren, en ingeval de executant een leek is op dit gebied, dient de notaris hem daarin te adviseren. In alle gevallen zal de notaris de personalia van de belangstellenden controleren. Bij veilingen waarvoor veel belangstelling bestaat kan de notaris een inschrijvingstermijn voor de geïnteresseerden instellen.

8 De notaris dient te onderzoeken of het hypotheekrecht niet teniet is gegaan doordat de vordering waarvan het afhangt is voldaan. Is de executant iemand die zijn vordering en het daarmee verbonden hypotheekrecht van een ander heeft ontvangen, dan dient de notaris te onderzoeken of er een rechtsgeldige cessie is geweest.

9 Bij een executie waarbij een dochtermaatschappij van een bank het pand koopt, dient ervoor te worden gewaakt dat de debiteur en/of overige ingeschreven schuldeisers niet worden benadeeld door een verkoop onder de executiewaarde.

10 Een notaris moet zich onthouden van het middels een rechtspersoon, waarvan hij zelf de begunstigde of aandeelhouder is, aankopen van een onroerende zaak op een veiling waarvan hij zelf de notaris is. Een dergelijke aankoop is immers nietig.

11 De notaris moet in alle gevallen eisen dat de koopsom in zijn handen wordt gestort. Indien dan niet gebeurt, mag hij het proces-verbaal van toewijzing niet inschrijven. In ieder geval mag hij nooit in strijd met de waarheid verklaren dat de koopsom in zijn handen is voldaan, ook al leidt dit niet tot schade bij derden.

12 De Nederlandse wijze van het veilen van zeer veel panden op een vaste veilingdag brengt risico's met zich mee en daaraan moet het notariaat niet beginnen. 